\title{
Eosin Removal Properties of Organo-local Clay from Aqueous Solution
}

\author{
RAWAN AL-FAZE and FETHI KOOLI* \\ Taibah University, Department of Chemistry, POBox 30002 , \\ Al-Madinah Al-Munawwarah, 41477 Saudi Arabia. \\ *Corresponding author E-mail: fkooli@taibahu.edu.sa \\ http://dx.doi.org/10.13005/ojc/300237
}

(Received: February 22, 2014; Accepted: March 18, 2014)

\begin{abstract}
Local clay from Al-Madinah Al-Munawwarah was modified by a solution of cetyltrimethylammonium bromide (C16TMABr) at different initial concentrations. The organoclays were characterized by PXRD, TGA, FTIR and $\mathrm{N}_{2}$ adsorption isotherms. The ability of these samples to remove the dye eosin is evaluated. The removal properties of organoclays were dependent on the content of C16TMA cations, the initial concentrations of eosin, temperature of the removal process, the mass of the used organoclays. These organoclays exhibited removal percentages in the range of $80 \sim 100 \%$ and removed amounts of $50 \sim 68 \mathrm{mg}$ of eosin/ $\mathrm{g}$. The isotherms were fitted well in Langmuir model.
\end{abstract}

Key words: Eosin, Organic clays, cetyltrimethylammonium bromide, PXRD, TGA, FTIR.

\section{INTRODUCTION}

Many industries use dyes in order to color their products, and consume huge amount of water, resulting to a considerable generation of amount of colored wastewater. The presence of undesirable colored dyes results to significant disturbance in ecological systems, mainly due to their highly carcinogenic compounds ${ }^{1}$. Several methods for removal and disposal of these dyes may be required to solve this problem. One of the promising technology for wastewater treatment is the adsorption process ${ }^{2}$. The most widely used porous media for wastewater treatment is activated carbon (AC) which develops very high surface areas and possesses strong adsorption capacities ${ }^{3}$. However there are many factors that need to be considered while using these adsorbents. The two main criteria are the cost effectiveness and availability of the adsorbents. In order to decrease the cost of treatment, attempts have been made to find inexpensive alternative adsorbents. The clay minerals were used for the removal of organics and dyes from aqueous solutions, due to their natural abundant around the world and low cost ${ }^{4}$. Natural clay minerals contain inorganic cations which are strongly hydrated in aqueous solution, and confer their surface a hydrophilic character. Per consequent, they are good adsorbents for cationic compounds but not for anionic, and non-ionic or 
hydrophobic compounds ${ }^{5,6}$. Many studies were focused in surface modification of clay mineral by tailoring hydrophobicity of clay surfaces for target molecules in adsorption process ${ }^{7}$. Replacing the native cations such as $\mathrm{Na}^{+}, \mathrm{K}^{+}$and $\mathrm{Ca}^{+2}$ with quaternary ammonium cations will increase like dissolve like interaction during organic contaminant uptake from a solution.

To the best of our knowledge, no studies were reported on local clay mineral from Al-Madinah region in the literature as adsorbents for metals or organic compounds. In this case, we investigate the modification of local clay mineral by cetyltrimethylammonium bromide (C16TMABr) solution at different initial concentrations to improve the removal properties towards eosin dye. The removal of eosin was undertaken at different conditions, The obtained isotherms were analyzed using Langmuir and Frendlich models.

\section{EXPERIMENTAL}

\section{Materials and modification}

The local clay mineral (M6) was collected from Al-Madinah Al-Munawwarah, area, near AlAgoul Ouady. The sample was used without further purification. Different amounts of C16TMABr salt were dissolved into $50 \mathrm{ml}$ of mineral water, and mixed with two grams of M6 clay, for overnight at room temperature. The resulting products were collected by filtration, washing and drying at room temperature. The sample is denoted as X-C16TMA$M 6$ where $X$ corresponds to the number of mmoles of $\mathrm{C} 16 \mathrm{TMABr}$ to cation exchange capacity (CEC) ratio.

\section{Removal studies of eosin}

The removal experiments of eosin were performed in batch process. $0.100 \mathrm{~g}$ sample of M6 or organoclays were mixed with $10 \mathrm{ml}$ dye solution of different initial concentrations $\left(C_{j}\right)$ from 25 to 800 $\mathrm{mg} / \mathrm{L}$, in glass stopped tubes of $12 \mathrm{~mL}$ capacity. These tubes were shaken in a controlled water bath shaker at $25^{\circ} \mathrm{C}$. The supernatant of each tube was collected by centrifugation, for $10 \mathrm{~min}$ at 4700 r.p.m. The eosin concentration at equilibrium $\left(\mathrm{C}_{\mathrm{e}}\right)$ was determined from their absorbance characteristics in the UV-vis range at the wavelength of its maximum absorbance $515 \mathrm{~nm}$. Once $\mathrm{C}_{\mathrm{e}}$ was estimated, the removal capacity (qe $(\mathrm{mg} / \mathrm{g})$ ) was calculated as follows: $q_{m}=\left(c_{i}-c_{j}\right) \pi \frac{v}{m}$, where $m(g)$ is the amount of used clay and $\mathrm{V}(\mathrm{L})$ is the volume of the added dye solution. The removal percentage of eosin was calculated using the following relation:

$$
\mathrm{R} \%=\frac{\left(C_{i}-C_{\varepsilon}\right)}{C_{i}} x 100 .
$$

\section{Characterization}

The mineralogical phases in M6 clay and the success of the clay modification were followed up by a Bruker x-ray diffractometer Advance 8, with $\mathrm{Cu}-\mathrm{K} \alpha$ radiation source. The elemental chemical analysis was obtained using a Bruker AXS model S4 spectrometer. The thermogravimetric analysis (TGA) features were recorded on a TA instrument, model SDT600.The measurements were carried out in air flow of $10 \mathrm{ml} / \mathrm{min}$, and heated from 25 to $800 \mathrm{C}^{\circ}$, with a heating rate of $10 \mathrm{C}^{\circ} \mathrm{min}^{-1}$. The FTIR spectra were recorded using $\mathrm{KBr}$ pellets at a resolution of $4 \mathrm{~cm}^{-1}$, with a Shimadzu spectrometer. The specific surface areas (SSA) and total pore volume of the samples were determined from nitrogen adsorption isotherms at $77 \mathrm{~K}$, obtained from a Micromimetrics ASAP2020, after outgassing the samples overnight at $120^{\circ} \mathrm{C}$.

\section{RESULTS AND DISCUSSION}

\section{Characterization of M6 clay and organoclays derivatives}

The XRF analysis indicated that the most abundant oxides in $\mathrm{M} 6$ clay are $\mathrm{SiO}_{2}(58 \%), \mathrm{Al}_{2} \mathrm{O}_{3}$ $(15 \%)$ and $\mathrm{Fe}_{2} \mathrm{O}_{3}(10 \%)$, whereas $\mathrm{MgO}, \mathrm{K}_{2} \mathrm{O}, \mathrm{CaO}$, $\mathrm{Na}_{2} \mathrm{O}, \mathrm{MgO}, \mathrm{TiO}_{2}$ and $\mathrm{MnO}$ are present only in small quantities. The CEC value was estimated about 34 meq $/ 100 \mathrm{~g}(7)$. This values was lower than the reported values of CECs for pure clay minerals $(80-120 \mathrm{meq} / 100 \mathrm{~g})(7)$. Finally, the $\mathrm{pH}$ value of waterclay suspension was about 8.8 9.0, indicating a basic character of M6 clay.

The powder XRD pattern of the M6 clay indicated that a quartz (reflection at $0.324 \mathrm{~nm}$ ) was the dominant phase in this clay, in addition other minerals were found, including illite $(1.02 \mathrm{~nm})$, kaolinite $(0.702 \mathrm{~nm})$, and calcium carbonate or 
feldspars $(0.301 \mathrm{~nm})$. The smectite phase was difficult to be detected. However, its presence was not neglected, because the M6 clay exhibited a reasonable CEC value. After modification with C16TMABr solutions, we noted that the position of the reflections related to quartz, illite and kaolinite were not changed, indicating that these phases were not affected by the organic modification. However, a weak and broad reflection in the low angle ranges could be resolved for higher C16TMA CEC ratios. The low intensity was related to lower crystallinity of our organoclays ${ }^{8}$, and it could be related to less proportion of smectite in M6 clay. The presence of organic moieties will be confirmed by the TGA and FTIR techniques. Indeed, the organoclays exhibited similar TGA features with an additional mass loss in the range of $150{ }^{\circ} \mathrm{C}$ to 400 ${ }^{\circ} \mathrm{C}$, related to the oxidative decomposition of C16TMA cations ${ }^{9}$. The percentage of this mass loss increased with the used C16TMA/CEC ratios, and it varied between $3.0 \%$ to $10.0 \%$, at initial C16TMA CEC ratios from 0.38 to 1 , then it remained unchanged at higher ratios above 1.5. These values were lower to that reported for other organoclays prepared at the same C16TMA/CEC ratios ${ }^{8,10}$, and it was related to the low CEC value of the starting M6 clay. The loaded amounts of C16TMA cations were estimated using the method proposed by ${ }^{10}$, and presented in Table 1. there were differences between the amount of surfactant added and the amount of surfactant loaded.

The presence of C16TMA surfactants were confirmed by FTIR technique, with the detection of two new bands in the $2800-2950 \mathrm{~cm}^{-1}$ region, corresponding to asymmetric and symmetric
$\mathrm{C}-\mathrm{H}$ stretching bands ${ }^{11}$. The $\mathrm{CH}_{3}-\mathrm{N}$ asymmetric bending at $1474 \mathrm{~cm}^{-1}$ was overlapped with band of the carbonate species ${ }^{11}$. The intensity of the bands in the range of $2800-2950 \mathrm{~cm}^{-1}$ was directly related to the C16TMA contents in the organoclays, as reported by different authors. However, in our case, the intensity of the two bands varied slightly in M6 modified clays prepared from initial C16TMA/CEC ratios above 0.76 , although, the TGA data revealed different loadings of C16TMA cations. This disagreement between TGA and FTIR data could be related to the way of the preparation of $\mathrm{KBr}$ pellets. The FITR bands of the other phases were observed and did not shifted, supporting the idea that they were not affected by the organic modification.

The parent M6 clay exhibited a SSA of 62 $\mathrm{m}^{2} / \mathrm{g}^{-1}$ with a pore volume of $0.087 \mathrm{cc} / \mathrm{g}$. this value was close to that reported in the literature for clay minerals. After modification, a dramatic decrease of the SSA values was observed from $10.7 \mathrm{~m}^{2} / \mathrm{g}^{-1}$ to $2.3 \mathrm{~m}^{2} / \mathrm{g}^{-1}$, followed by a reduction in the pore volume from $0.031 \mathrm{cc} / \mathrm{g}$ to $0.008 \mathrm{cc} / \mathrm{g}$. This decrease was a result of the clay modification, and could be associated to the presence of organic cations between the clay layers, which blocked the access of nitrogen molecules to the interlayer spacing, The obtained SSA values were close to that reported for other organoclays ${ }^{8,9}$.

\section{Removal properties of Eosin Effect of C16TMA contents}

M6 and its organoclays at different initial C16TMA/CEC ratios, were tested in the removal of eosin at different initial concentrations (25 and 800

Table 1: Parameters obtained from the adsorption models

\begin{tabular}{|c|c|c|c|c|c|c|c|}
\hline \multirow[b]{2}{*}{ Samples } & \multicolumn{4}{|c|}{ Langmuir } & \multicolumn{3}{|c|}{ Freundlich } \\
\hline & Expt.R & $\mathbf{q}_{\max }^{+}$ & $\mathrm{K}_{\mathrm{L}}^{-}$ & $\mathbf{R}^{2}$ & $1 / n$ & $\mathrm{~K}_{\mathrm{F}}$ & $\mathbf{R}^{2}$ \\
\hline M6 & 0.00 & 4.08 & 0.0032 & 0.9512 & 0.7839 & 0.023 & 0.9433 \\
\hline 0.4- C16TMA-M6 & 0.16 & 66.65 & 0.0025 & 0.726 & 0.7430 & 0.39 & 09868 \\
\hline 0.8-C16TMA-M6 & 0.31 & 55.55 & 0.0233 & 0.9231 & 0.3277 & 5.45 & 0.9450 \\
\hline 1.6-C16TMA-M6 & 0.63 & 50.01 & 0.081 & 0.9963 & 0.3126 & 11.89 & 0.8933 \\
\hline 2.4-C16TMA-M6 & 0.69 & 48.20 & 0.096 & 0.957 & 0.2758 & 9.90 & 0.7400 \\
\hline 3.2-C16TMA-M6 & 0.63 & 50.25 & 0.104 & 0.980 & 0.300 & 10.16 & 0.8201 \\
\hline
\end{tabular}

${ }^{+}(\mathrm{mg} / \mathrm{g}),-(\mathrm{L} / \mathrm{mg})$, Expt.R stands for experimental C16TMA/CEC ratios 
ppm) and at $25^{\circ} \mathrm{C}$. As we expected, the raw M6 clay exhibited lower removal percentage of $5 \%$, independently of the used initial concentrations. This fact was related to the Coulombic repulsion between the negatively charged dye molecules and the negatively charged surface M6 layers. The removal percentage was improved after C16TMA modification, and an average value of $98 \%$ was achieved using $\mathrm{C}_{i}$ of $25 \mathrm{mg.L} \mathrm{L}^{-1}$, independently of C16TMA loadings. As the $C_{i}$ values increased to $800 \mathrm{mg} / \mathrm{L}$, the removal percentage decreased and varied from $49 \%$ to $70 \%$, and it was related to the loading amounts of $\mathrm{C} 16 \mathrm{TMA}^{+}$cations. A maximum value of $70 \%$ was obtained for the sample 1.52 C16TMA-M6. The removal capacity was improved with the increase of initial concentrations, and depended on the loading of $\mathrm{C} 16 \mathrm{TMA}^{+}$cations, it reached a maximum value of $56 \mathrm{mg} / \mathrm{g}$ for the sample 1.52-C16TMA-M6. For further studies, the sample 1.52-C16TMA-M6 was used, unless it is stated.

\section{Effect of Adsorbent dosage}

The adsorbent dosage is an important parameter useful in the determination of the capacity of an adsorbent for a given initial adsorbate concentration. In our case, different masses from $0.050 \mathrm{~g}$ to $1.00 \mathrm{~g}$ of $1.52-\mathrm{C} 16 \mathrm{TMA}-\mathrm{M} 6$ were added to $10 \mathrm{ml}$ of $\mathrm{C}_{i}$ of $200 \mathrm{mg} / \mathrm{L}$. The removal percentage of eosin was close to $98 \%$, and remained unchanged with added masses higher than $0.050 \mathrm{~g}$. In the other hand, the removal capacity decreased with increasing the organoclay mass. The decrease in removed dye was a result of higher adsorbent mass which provided more active adsorption sites. Thus resulted in the adsorption sites remaining unsaturated during the adsorption. The mass of $0.100 \mathrm{~g}$ was selected during our studies.

\section{Effect of used volume eosin solution}

The effect of the dye volume used during the removal process at fixed $C_{i}$, has not been reported frequently in the literature. Different $C_{i}$ volumes of $200 \mathrm{mg} / \mathrm{L}$ were added to a fixed mass of $0.1 \mathrm{~g}$ of organoclay. The removal percentage of eosin decreased as the used volume of eosin solution increased, and a maximum of $98 \%$ removal was achieved using small volumes varying from 5 to $10 \mathrm{~mL}$. At higher added volumes, a removal percentage of $25 \%$ was achieved. This result could be attributed to the smaller amount of surface area available to adsorb higher number eosin molecules when the volume was increased. Thus the volume of $10 \mathrm{~mL}$ was fixed for further studies.

\section{Effect of $\mathrm{pH}$}

The $\mathrm{pH}$ of dye solution plays an important role on the adsorption capacity of the removal agents, because it affected the ionization degree of the adsorbate and the surface property of the adsorbent ${ }^{12}$. The $\mathrm{pH}$ value of eosin solution $\left(\mathrm{C}_{i}\right.$ of $200 \mathrm{mg} / \mathrm{L}$ ) was adjusted from 2 to 11 , using either dilute $\mathrm{HCl}$ or $\mathrm{NaOH}$ solutions, while other conditions were kept constant. Since eosin was precipitated under acidic conditions at $\mathrm{pH}$ values lower than 2 12, all our studies were carried out at $\mathrm{pH}$ above 3 . The 1.52-C16TMA-M6 clay exhibited a removal percentage of $98 \%$, and it was independent of the $\mathrm{pH}$ values. This surprising data indicated that either the type of charges on the surface clay was not affected by the acidic values of the $\mathrm{pH}$ solution, or the addition of the organoclay to eosin solution has changed considerably the final $\mathrm{pH}$ value of the mixture. Indeed, the final $\mathrm{pH}$ values after addition of clay was in the range of 8 to 9 to all the mixture of organoclays and eosin solutions.

\section{Effect of temperature}

The removal of eosin was performed at different temperatures from $30{ }^{\circ} \mathrm{C}$ to $50{ }^{\circ} \mathrm{C}$, using different $C_{\text {, from }} 25-800 \mathrm{mg} / \mathrm{L}$, while other conditions were kept constant. We have found that the removal process was sensitive to the changes of temperatures at higher $C_{i}$ values, above $500 \mathrm{ppm}$. Our data revealed that the removal of eosin involves an endothermic process ${ }^{12}$. In general, the removal percentage was improved at higher $C_{i}$ values with increasing the temperature in the range of 30 to 50 ${ }^{\circ} \mathrm{C}$. It varied from $52 \%$ to $86 \%$ for $\mathrm{C}_{\mathrm{i}}$ of $800 \mathrm{mg} / \mathrm{L}$, associated with an increase in removal capacity from $52 \mathrm{mg} / \mathrm{g}$ to $68 \mathrm{mg} / \mathrm{g}$ at $50{ }^{\circ} \mathrm{C}$, The improvement of removal capacity was related to an increase in the mobility of the eosin ions ${ }^{13}$.

\section{Effect of initial concentration}

The removal percentage of eosin was highly concentration dependent. It increased with decreasing $C_{i}$ values, where it reached a maximum of $99 \%$ for lower Ci values. and decreased to $60 \%$ at higher $\mathrm{C}_{i}$ values. In other hand, an improvement in removal capacity $(\mathrm{mg} / \mathrm{g})$ was achieved from 1.2 
$\mathrm{mg} / \mathrm{g}$ to $52 \mathrm{mg} / \mathrm{g}$, with increasing eosin concentrations. At lower $C_{i}$ values, sufficient adsorption site are available for the removal of low number of dye ions. Contrarily, at higher $\mathrm{Ci}$ values, the number of eosin ions were more as compared to available sites ${ }^{14}$.

\section{Adsorption isotherms}

The experimental adsorption data have been subjected to different adsorption isotherms namely Langmuir ${ }^{15}$, and Freundlich ${ }^{16}$ models in the aims to determine the adsorption capacity of the modified M6 clays, to obtain a good picture of the surface and to find the best model for the design purpose.

The Langmuir isotherm is applicable if the monolayer coverage of adsorbent with adsorbate takes place on a homogeneous adsorbent surface. The Langmuir coefficients $K_{L}$ and $q_{m}$ representing respectively the adsorption equilibrium constant and maximum adsorption capacity, have been determined from the intercepts and slopes of the plot of $\mathrm{Ce} / q \mathrm{qe}$ versus $\mathrm{Ce}$, according the equation $\frac{C_{s}}{q_{s}}-\frac{1}{q_{m x x} K_{s}}+\frac{C_{s}}{q_{m x x}}$ : where, $\mathrm{q}_{\mathrm{e}}$ is the amount adsorbed at equilibrium $(\mathrm{mg} / \mathrm{g}), \mathrm{C}_{\mathrm{e}}$ is equilibrium concentration of the adsorbate $(\mathrm{mg} / \mathrm{l})$, and $\mathrm{q}_{\max }(\mathrm{mg} /$ g) and $K_{L}(1 / m g)$. The Langnuir $\mathrm{q}_{\max }$ and $\mathrm{K}_{\mathrm{L}}$ are presented in Table 2. The average removed of Eosin $\left(\mathrm{q}_{\max }\right)$ was close to $50 \mathrm{mg} / \mathrm{g}$ for all the samples.
The Freundlich isotherm is an empirical equation assuming that the adsorption process takes place on heterogeneous surfaces; the adsorption capacity $\left(\mathrm{q}_{\mathrm{e}}\right)$ is related to concentration at equilibrium $\left(\mathrm{C}_{\mathrm{e}}\right)$ of eosin. A linear form of the Freundlich equation is generally expressed as: $L n q_{\varepsilon}-L n K_{z}+\frac{1}{n} L n C_{c}$. Where $\mathrm{K}_{\mathrm{F}}$ indicates the adsorption capacity and $\mathrm{n}$ is the adsorption intensity. The magnitude of $n$ reveals the favourability of the adsorption with values of $1 / n$ are in the range of 0 and 1. ${ }^{16}$ The plot of $\mathrm{Lnq}_{\mathrm{e}}$ versus $\mathrm{LnC}_{\mathrm{e}}$ is employed to evaluate the intercept $K_{F}$ and the slope $1 / n$.

\section{CONCLUSIONS}

This study indicated that the local clay from Al-Madinah Al-Munawwarh could be considered as eosin removal agent from polluted water with colorant dye. The modification of raw clay with C16TMA surfactants was a crucial step to improve its removal effectiveness. A lower starting C16TMA/ CEC ratio of 0.4 , was enough to increase the removed amounts from 8 to $66 \mathrm{mg} / \mathrm{g}$. By increasing this ratios, we were able to improve the loaded amount of C16TMA cations, with an average removed amounts of $50 \mathrm{mg} / \mathrm{g}$ of eosin.

\section{ACKNOWLEDGMENTS}

The authors would like to thank King AbdulAziz City for Science and Technology (KACST), Riyadh, Saudi Arabia for the financial support (project code: P-S-12-5).

\section{REFERENCES}

1. Pielesz, A. J. Mol. Struct. 1999, 512, 337-344

2. Forgacs, E.; Cserhati, T.; Oros, G. Environ. Int. 2004, 30, 953-971.

3. Gupta, V. K.; Suha, S. J. Environ. Manage. 2009, 90, 2313-2342.

4. Alleni, S. J.; Koumanova, B. J. Univ. Chemical Technol. Metall. 2005, 40, 175-192.

5. Espantaleon, A. G.; Nieto, J. A.; Fernandez, M.; Marsal, A. Appl. Clay Sci. 2003, 24, 105110.

6. Ray, S. S.; Okomoto. M. Prog. Polym. Sci. 2003,
28, 1539-1641.

7. Meier, L. P.; Khar, G. Clays Clay Miner. 1999, 47, 386-388.

8. Kooli, F.; Yan, L.; AIShahateet, S. F.; Messali, M.; Bergaya, F. Appl. Clay Sci. 2009, 43, 357363 .

9. Kooli, F. Thermochim. Acta, 2013, 551, 7-13.

10. Ramos Vianna, M. M. G.; Deweck, J.; Kozievitch, V. F. J.; Valenzuela-Diaz, F. R.; Buchler, P. M. J. Thermal. Anal. Calorim. 2005, 82, 595-602.

11. Kooli, F. Langmuir, 2009, 25, 724-730. 
12. Ansari, R.; Mosayebzadeh, Z. Iranian Polym. J. 2010, 19, 541-551.

13. Mane, V. S.; Mall, I. D.; Srivastava, J. Environ. Manage. 2007, 84, 390-400.

14. Ju, D. J.; Byun, I. G.; Park, J. J.; Lee, C. H. Ahn, G. H.; Park, T.J. Bioresource Technol. 2008,
99, 7971-7975.

15. Langmuir, I. J. Amer. Chem. Soc. 1918, 40, 1361-1403.

16. Freundlich, U. J. Phys. Chem. 1906, 57, 385470. 